\title{
An analysis of underlying constructs affecting the choice of accounting as a major
}

\author{
Duc Tai Do ${ }^{a}$, Thi Huong Nguyen ${ }^{b}$, Son Tung Ha ${ }^{c^{*}}$, Manh Dung Tran', Huu Anh Nguyen ${ }^{c}$ and Duc \\ Dinh Truong ${ }^{\mathrm{a}}$
}

\author{
${ }^{c}$ National Economics University, Vietnam \\ C H R O N I C L E

\begin{tabular}{l}
\hline Article history: \\
Received: July 92019 \\
Received in revised format: July \\
192019 \\
Accepted: August 25, 2019 \\
Available online: \\
August 26, 2019 \\
\hline Keywords: \\
Determinants \\
Employment \\
Accounting graduates
\end{tabular}

${ }^{a}$ University of Labor and Social Affairs, Vietnam

${ }^{b}$ Faculty of Accounting, Trade Union University, Vietnam

\section{A B S T R A C T}

This study was conducted to investigate the effects of different factors influencing on employment of accounting graduates in Hanoi, Vietnam. The necessary data were collected using some questionnaires from accounting graduates working for enterprises in the area of Hanoi, Vietnam. Based on the data collected, Cronbach's Alpha, Exploratory factor analysis (EFA) and regression model were implemented for learning the effect of each independent variable on employment of accounting graduates. The results show that five determinants including accounting student factor (ASPF), Part-time work before graduation (PWBG), information technology (IT), University factors (UF) and Related legal and policy environment (RLPE) had positive relationships with the employment of accounting graduates. Based on the findings, some recommendations were given for improving the employment of accounting graduates in the area of Hanoi, Vietnam.

\section{Introduction}

Employment plays an important role in social life, it is indispensable for each individual and the whole economy and it is a core and throughout issue in economic activities, has a close relationship with economy and society and dominates all personal and social activities. The Ministry of Education and Training (MoET) of Vietnam has requested universities and colleges throughout the country to report on employment status of regular graduates every year. This is a mandatory requirement, which is a condition for the department to consider the annual enrollment of schools. In addition, the survey of graduate students is one of the criteria of the accreditation of universities and colleges according to university rules and guidelines of the MoET. The orientation of accounting training in accordance with the future of the labor market is always the goal of universities to affirm their brand in training. In recent years, accounting is one of the professions that are recognized by society, needs the most human resources because all organizations, firms, and business units need accounting. Job opportunities for accountants are very large. Some graduates can have a stable job but there are still many students who find it difficult to find a suitable job. The capture of information after graduation of alumni about their work as having properly trained majors, income, degree of career development, and others help universities know how to change and adjust to meet the employers' needs. In additiondeterminants influencing the employment of accounting graduates in recent years has not been paid attention, evaluated and fully analyzed. Through studies in the context of Vietnam and in the world, we see a gap among the prior studies such as (i) focusing only on analyzing and evaluating the rear job graduation of students or the financial activities with employment issues; (ii) through running Logit and Probit Model we learn the effects of different

* Corresponding author.

E-mail address: tunghs@neu.edu.vn (S.T. Ha) 
factors influencing on the jobs. Based on literature review, we used a qualitative research methodology based on an in-depth interviews with four lecturers with much experience in accounting of some universities in the area of Hanoi, Vietnam. At the same time, we interviewed five experts working as directors, chief accountants and general accountants in Hanoi firms. The results of the interviews include the employment of accounting grauates and what determinants affect the employment of accounting graduates. Based on the results of qualitative research and the inheritance of previous studies, we design the model of determinants influencing the employment of accounting graduates. Moreover, we develop and validate the scales of factors affecting the employment of accounting graduates, thus providing some recommendations to enhace more opportunities for accounting graduates for getting a job.

\section{Research Model}

Based on the results of previous studies and based on the results of qualitative research through expert interviews, some variables are explained as:

\subsection{Factor of accounting graduate}

Begg and Fischer (2000) suppose that human capital is the total qualification that an employee accumulates. It is appreciated for its potential to generate income in the future by assuming that wage differences reflect the difference in labor productivity. People with higher productivity will earn higher income and wages and a fundamental argument is that education and training create higher labor productivity. Along with age factor, experience and qualification are the main factors influencing income. There are many effects of age on dynamic activities, adaptability to surrounding environment and conditions, so they are ready to implement newer challenges to assert themselves and desire to have higher income. Older accountants with good job experience normally have a better job position with high income and wish to have a stable and safe work. The ability to hear and adapt to the changing labor market, the change of technology and new technologies into production will help workers get better jobs. Occupational culture of workers includes attitudes and behaviors of employees towards human values (ethics, professional conscience, attitude, working style, mind law enforcement, labor discipline, behavioral skills, etc). Employees who are aware of good labor discipline also help other more often and help organization gain higher productivity, safer jobs, etc. especially in informal business establishments where there are not many labor law policies applied. Luong (2008), Nguyen et al. (2011) used Logit and Probit models to assess the employability of workers, and the relationship between qualifications and employment. The results show that qualifications had a positive relationship with employment. Tran (2011) stated that because of the need for money, many people became stuck in jobs they did not like. Although this may be the right move for an accountant but this is not what he/she may do for the rest of his/her life. The reason why many people should pursue passion rather than money is to gain the ability to get a better job, be more productive, have a reason to move forward, feel satisfied and less stressed and build strong and positive relationships. So a hypothesis is given as:

$\mathrm{H}_{1}$ : Accounting graduate has an impact on the its employment in the area of Hanoi.

\subsection{Factor of part-time job before graduation}

The trend of students going to do more work is a movement for young people. On the one hand, doing more to earn more income, on the other hand, the students also wish to have more opportunities to learn the reality, practice their style and independence. Many accounting students cannot work in suitable accounting jobs and they only work in supplementary jobs such as cashier, sales, customer service, receptionist, running staff tables in restaurants, bars, delivery or security staff in companies. Their works are not associated with accounting and only help them get some experience and develop their basic skills. Nguyen (2009) analyzed the results of a survey of 480 students of the University of Foreign Languages - National University and showed that the majority of students believed they needed to work more if necessary. Nguyen concluded that overtime work was a great demand of students of Foreign Language University, National University nowadays. Le et al. (2016) conducted a survey among 96 students of the Foreign Trade University and explained that 30 students (31.25\%) believed that it was very important to work part-time in the study process at the school; 51 students $(53.12 \%)$ stated it was important, only a few students rated it unimportant. The authors concluded that students who do overtime before graduation would have a higher chance of getting a job before graduation. So we give a hypothesis as:

$\mathrm{H}_{2}$ : The factor of part-time work before graduation may influence on the post-graduate employment of accounting students in Hanoi.

\subsection{Factor of information technology}

According to Tran (2018), when information technology basics are growing at a dizzying pace, students gain good experiences and create jobs right from their university seats. On the other hand, when the university cooperates with businesses, it will create many job opportunities for students. Information technology plays a leading role in the accounting information system. The application of information technology (IT) to the accounting work has three levels, i.e. semi-manual processing level; level of automation of accounting work and the level of management automation. The first level is popular among enterprises in Vietnam, in this form, enterprises do accounting with accounting software, information technology has penetrated into many fields. Traditional accounting practices have been completely altered, particularly the way accounting data is handled by the role of information technology. In fact, IT has automated traditional accounting books. The accounting software 
package can come with a wide range of specialized features or a generic program that can be customized to suit the business operations of the businesses. Businesses often choose accounting software based on the scale of their operations and the number of users accessing the Accounts System. In addition, a tax declaration software is one of useful of information technology to help accountants complete works of tax accounting in firms. So, we give a hypothesis as:

$\mathrm{H}_{3}$ : Information technology has an impact on the employment of accounting graduates.

\subsection{Factor of university}

According to Nguyen (2013), in order to have technical expertise, workers need to be trained, granted diplomas or certificates of the training levels of the national education system, with professional knowledge and practical skills. At different levels, depending on the level of training, it is possible to solve specialized issues that meet the requirements of the labor market; have research and creative capabilities; solve scientific and technological issues. Luong (2015) stated that the role of academic advisors is very important and indispensable in the credit-based training process. Each academic advisor is a key factor in the university -student relationship - the labor market, is an academic and employment consultant for students, and accompanies them throughout learning and training process at the school. Luong affirmed that the academic advisor has the function of supervising, consulting and orienting career choices of students; advise the school on training according to the needs of society. The academic advisor also has the task of consulting career orientation and employment for students, etc. Since then, he presented several solutions to improve the quality of training in universities through academic counseling. Tran (2018) affirmed, in the context of integration, labor resources are facing many challenges, especially new graduates. The quality of training and soft skills of students in the learning process is a decisive factor for the output quality of students. University brand associated with students with jobs analyzed by Luong $(2008,2015)$. Criteria for the rate of students having jobs is considered an important requirement to determine the quality of education as well as brand of universities. Many universities have been promoting training policies that are directly linked to the needs of enterprises, training according to enterprises' demands. Universities are focusing on implementing measures to improve the quality of training such as developing teaching staff, strengthening facilities, strengthening business connections, developing training and quality control programs input, quality of training and output quality. It emphasizes the accreditation of education quality according to accreditation standards approaching ASEAN regional standards and survey and publication and improve the employment rate of graduate students. Based on that, we design a hypothesis as:

$\mathrm{H}_{4}$ : University factors influence on the employment of accounting graduates.

\subsection{Factor of related legal and policy environment}

Keynes (1994), when studying consumption for investment by enterprises, stated that increasing investment plays a decisive role in the size of employment. Investment increases aggregate demand and employment and the state plays an active role in intervening in aggregate demand, output and employment. Tran (2011) set out the regimes of production and business establishments that affect the salary or income of employees. Le et al. (2016) conducted a survey of 96 students of the Foreign Trade University of Vietnam and the results showed that 41 students $(42.71 \%)$ reported that updating information on the labor market was very important, 37 students (38.54\%) though it was important, while the number of students who rated it unimportant was $18.75 \%$. The role of policy regulations is quite important in adjusting the employment of enterprises in general. If there are no regulations on working time, working conditions, wages, etc., the employment of employees depends largely on how employers use labor (Nguyen, 2014). Therefore, employment first depends on whether there is a policy or no employment policy. The labor market policy is the State's intervention tools in the work of the labor market with a view to better ensuring employment opportunities for employees, providing jobs that are more commensurate with ability and bring higher income for workers. So we design as a fifth hypothesis as:

$\mathrm{H}_{5}$ : Related legal and policy environment factors influence on the employment of accounting graduates.

From the above analysis, we design a research model shown in Fig. 1 as follows,

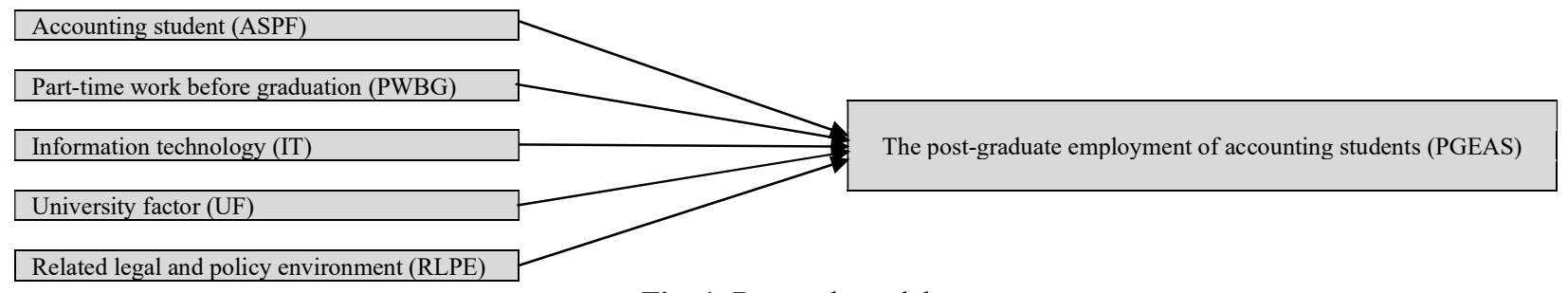

Fig. 1. Research model

\section{Research Methodology}

In order to achieve the objectives of this paper, we based our work on the theory of previous studies and the results of qualitative research through expert interviews and model analysis. On the other hand, we combined with the inductive method to 
verify, based on qualitative research results, to adjust and add observation variables to the questionnaire for conducting quantitative research. Inheriting the results of studies conducted by Keynes (1994), Begg and Fischer (2000), Nguyen (2009), Tran (2011), Nguyen (2013), Luong (2015), Le et al. (2016), Tran (2018); and using qualitative research approach through interviews with experts to perform quantitative research, we have identified five determinants that affect the employment of accounting graduates, i.e. (i) Accounting student factor (ASPF), (ii) Part-time work before graduation (PWBG), (iii) Information technology (IT), (iv) University factor (UF) and (v) Legal environment \& relation policy (LERP). Then, we conducted a questionnaire consisting of 24 observation variables with a 5-point Likert scale. Independent variables are measured from 1 "with not effect" to 5 "with strong effect". The method of data collection was done through the survey and subjects are accounting graduates working in the area of Hanoi, the capital of Vietnam.

We sent 300 questionnaires and received the feedback of 270. After checking the information on the votes, there were 255 questionnaires with full information for data entry and analysis, the size of this sample was consistent with study of Hair et al. (2006) $(\mathrm{n}=50+8 \times 5=50+8 \times 5=90)$. Therefore, the rest of observations for the model are 255 surveys, including $100 \%$ participants who are chief accountants, general accountants, accounting firms in Hanoi's staff accountants and other positions (business staff, office staff). Participants mostly have bachelor's degree or higher (100\%). As can be seen, all participants are at high quality of accounting knowledge, and this makes surveys' answer more reliable.

Then, we have employed EFA analysis and regression model for investigating the impact levels of determinants on the employment of accounting graduates in the area of Hanoi capital of Vietnam.

Dependent variable: The employment of accounting graduates (or students).

Independent variables: The independent variables are described as below:

\begin{tabular}{|c|c|}
\hline Code & Variables and Its Attributes \\
\hline \multicolumn{2}{|c|}{ Accounting student factor (ASPF) } \\
\hline ASPF1 & Professional knowledge, other supporting knowledge of accounting and education level \\
\hline ASPF2 & Graduation results of students \\
\hline ASPF3 & Work skills including hard skills and soft skills \\
\hline ASPF4 & Passion for career \\
\hline ASPF5 & Graduation time \\
\hline ASPF6 & Student's age \\
\hline ASPF7 & Gender of students \\
\hline \multicolumn{2}{|c|}{ University factor (UF) } \\
\hline UF1 & School brand \\
\hline UF2 & School facilities \\
\hline UF3 & Training program \\
\hline UF4 & Training coordination of schools and firms \\
\hline UF5 & Specialized lecturers and academic advisors \\
\hline \multicolumn{2}{|c|}{ Part-time work before graduation (PWBG) } \\
\hline PWBG1 & Has contacted, explored reality about work \\
\hline PWBG2 & Being trained in skills, self-reliance \\
\hline PWBG3 & Work experience \\
\hline \multicolumn{2}{|c|}{ Related legal and policy environment (RLPE) } \\
\hline RLPE1 & Labor market policy on job search assistance \\
\hline RLPE2 & Labor market policy on labor market information \\
\hline RLPE3 & Labor market policy on providing training and retraining opportunities \\
\hline RLPE4 & Labor market policy on business start-up support \\
\hline RLPE5 & Labor market policy on income support for unemployed workers \\
\hline \multicolumn{2}{|c|}{ Information technology (IT) } \\
\hline IT1 & Application of information technology in the search job \\
\hline IT2 & Understanding and proficient use of accounting software \\
\hline IT3 & Understanding and proficient use of tax declaration software \\
\hline IT4 & Robot replaces people in accounting work \\
\hline
\end{tabular}

\section{Results and Discussions}

\subsection{Results}

\section{Descriptive statistics}

Information of data collected is shown in Table 1. Data in Table 1 show that among the 255 respondents, other positions accounted for $18.8 \%$, accounting staff were accounted for $45.1 \%$, general accounting made up $27.8 \%$, while the remaining 21 were chief accountant, accounted for $8.2 \%$. Of these, respondents for less than 1 year was 83 , accounted for $32.5 \%$, Over 3 years was accounted for $22.7 \%$, while the remaining 114 , were from 1 to 3 years, accounted for $44.7 \%$ 
Table 1

Respondents by Jobs and Work Experience

\begin{tabular}{|c|c|c|c|c|}
\hline & $\mathbf{n}$ & Percent & Valid Percent & Cumulative Percent \\
\hline \multicolumn{5}{|l|}{ By Jobs } \\
\hline Other positions & 48 & 18.8 & 18.8 & 18.8 \\
\hline Accounting staff & 115 & 45.1 & 45.1 & 63.9 \\
\hline General accounting & 71 & 27.8 & 27.8 & 91.8 \\
\hline Chief accountant & 21 & 8.2 & 8.2 & 100,0 \\
\hline \multicolumn{5}{|l|}{ By Experience } \\
\hline Less than 1 year & 83 & 32.5 & 32.5 & 32.5 \\
\hline Over 3 years & 58 & 22.7 & 22.7 & 55.3 \\
\hline From 1 to 3 years & 114 & 44.7 & 44.7 & 100.0 \\
\hline
\end{tabular}

\subsection{Quality scale analysis}

By using scale analysis, it can eliminate invalid variables and reduce errors in the research model. Therefore, only variables which have total correlation coefficients (Corrected Item - Total Correlation) greater than 0.3 and Cronbach's Alpha coefficients equal or greater than 0.6 were accepted (Hoang \& Chu, 2008). By analyzing Cronbach's Alpha analysis of determinants have an influence on the post-graduate employment of accounting students (five determinants with 24 attributes), the result is presented in Table 2 .

Table 2

Results of analysis of Determinants Confidence of Scales in the Model

\begin{tabular}{lcc}
\multicolumn{1}{c}{ Determinants } & $\mathrm{n}$ & $\begin{array}{c}\text { Corrected Item-Total } \\
\text { Correlation }\end{array}$ \\
\hline Accounting student factor (ASPF) & 7 & 0.862 \\
University factor (UF) & 5 & 0.751 \\
Part-time work before graduation (PWBG) & 3 & 0.828 \\
Related legal and policy environment (RLPE) & 5 & 0.864 \\
Information technology (IT) & 4 & 0.448 \\
\hline
\end{tabular}

The result shows that, all Cronbach's Alpha coefficients of population are above 0.6; all Corrected Item - Total Correlation of observed variables are above 0.3. So, all variables of research model are suitable for next analyses (Hair et al., 2006).

\subsection{Exploratory factor analysis (EFA)}

EFA were conducted and we have used the method of extracting coefficients which were Component Analysis and Varimax and the results are presented in Table 3 as follows,

Table 3

KMO and Bartlett's Test

\begin{tabular}{llc}
\hline Kaiser-Meyer-Olkin Measure of Sampling Adequacy. & .904 \\
\hline Bartlett's Test of Sphericity & Approx. Chi-Square & $3,910.443$ \\
& Df & 276 \\
& Sig. & 0.000 \\
\hline
\end{tabular}

The results of factor analysis in Table 3 show that $0.5<\mathrm{KMO}=0.904<1$. Bartlett's yields sig. $=0.000<0.05$. It means variables in the whole are interrelated. After implementing the rotation matrix, five determinants had factor load greater than 0.5 and eigenvalues greater than 1; the variance explained was $69.30 \%$, which means that research data analyzing factor discovery was appropriate. Through the quality assurance of the scale and the test of the EFA model, we have identified five factors influencing the employment of accounting graduates.

\subsection{Regression model analysis}

Based on adjusted model after the exploratory factor analysis, we have a multiple regression model as follows,

PGEAS $=\alpha+\beta_{1}$ ASPF $+\beta_{2}$ PWBG $+\beta_{3} I T+\beta_{4}$ UF $+\beta_{5}$ RLPE

Table 4

Model Summary

\begin{tabular}{|c|c|c|c|c|c|}
\hline Model & $\mathrm{R}$ & R Square & $\begin{array}{c}\text { Adjusted R } \\
\text { Square }\end{array}$ & $\begin{array}{c}\text { Std. Error of the } \\
\text { Estimate }\end{array}$ & Durbin-Watson \\
\hline 1 & $.450^{\mathrm{a}}$ & .687 & .684 & 1.605 & 1.880 \\
\hline
\end{tabular}

a. Predictors (Constant): IT, ASPF, PWBG, RLPE, UF

b. Dependent Variable: PGEAS 
Table 5

ANOVA $^{\mathrm{a}}$

\begin{tabular}{|c|c|c|c|c|c|c|}
\hline \multicolumn{2}{|r|}{ Model } & Sum of Squares & Df & Mean Square & \multirow{2}{*}{$\frac{F}{8.103}$} & Sig. \\
\hline & Regression & 12.189 & 5 & 21.038 & & $.000^{\mathrm{b}}$ \\
\hline & Residual & 91.168 & 249 & 10.366 & & \\
\hline & Total & 91.356 & 254 & & & \\
\hline
\end{tabular}

a. Dependent Variable: PGEAS

b. Predictors: (Constant): IT, ASPF, PWBG, RLPE, UF

Table 6

Coefficients $^{\mathrm{a}}$

\begin{tabular}{|c|c|c|c|c|c|c|c|}
\hline \multirow[t]{2}{*}{ Model } & \multicolumn{2}{|c|}{$\begin{array}{l}\text { Unstandardized } \\
\text { Coefficients }\end{array}$} & \multirow{2}{*}{$\begin{array}{c}\text { Standardized } \\
\text { Coefficients } \\
\text { Beta }\end{array}$} & \multirow[t]{2}{*}{$\mathrm{T}$} & \multirow[t]{2}{*}{ Sig. } & \multicolumn{2}{|c|}{$\begin{array}{c}\text { Collinearity } \\
\text { Statistics }\end{array}$} \\
\hline & B & $\begin{array}{l}\text { Std. } \\
\text { Error }\end{array}$ & & & & Tolerance & VIF \\
\hline (Constant) & -3.979 & 2.323 & & -12.336 & .000 & & \\
\hline ASPF & 3.038 & .960 & .331 & 3.396 & .007 & .553 & 1.809 \\
\hline UF & 6.064 & .613 & .162 & 4.493 & .022 & .257 & 1.888 \\
\hline PWBG & 1.017 & .901 & .321 & 1.183 & .009 & .290 & 1.445 \\
\hline RLPE & 3.014 & .904 & .082 & 1.144 & .009 & .332 & 1.912 \\
\hline IT & 2.028 & .607 & .316 & 1.423 & .007 & .719 & 1.391 \\
\hline
\end{tabular}

Data in Tables 4, 5 and 6 show that:

(i) Multicollinearity testing: all variance inflation factor (VIF) of independent variables are under 2, so multicollinearity of model is low (Hoang \& Chu, 2008). Therefore, this regression model does not have any violation of the CLRM basic assumption.

(ii) Durbin - Watson statistic which is used to test the autocorrelation of residuals indicates the model does not violate when using multiple regression method because Durbin - Watson value is 1.880 (in the interval of 1 and 3 ). In other words, the model is indicated no autocorrelation of residuals (Hoang \& Chu, 2008).

(iii) ANOVA testing result: Level of significant (Sig.) $=0.000$ implies that multiple regression model is suitable with data.

(iv) Coefficient of $\mathrm{R}^{2}$ (R Square) $=0.687$, which means $68.7 \%$ of the total variation in the employment of accounting graduates will be explained by the regression model.

Research model result indicates that all independent variables accounting student factor (ASPF), Part-time work before graduation (PWBG), Information technology (IT), University factors (UF) and Related legal and policy environment (RLPE) are significant (because Sig. $<0.05$ ) to the employment of accounting graduates and the model can be summarized as follows,

$$
P G E A S=0.331 \times A S P F+0.162 \times U F+0.321 \times P W B G+0.082 \times R L P E+0.316 \times I T
$$

Research model result indicates that all independent variables including accounting student factor (ASPF), Part-time work before graduation (PWBG), Information technology (IT), University factors (UF) and Related legal and policy environment (RLPE) are significant (because Sig. $<0.05$ ) an dinfluence on the employment of accounting graduates. So hypotheses of $\mathrm{H}_{1}$, $\mathrm{H}_{2}, \mathrm{H}_{3}, \mathrm{H}_{4}, \mathrm{H}_{5}$ are accepted.

\subsection{Discussions}

\section{Accounting student factor}

Foreign language skills are considered as one of the reasons why accountants find it difficult to find jobs. The survey has indicated that accountants with good knowledge of languages including English, Japanese or Korean, etc. will have many good job opportunities with attractive level of salary, especially when Vietnam has integrated with the world economy, increasingly many foreign partners investing in Vietnam, led by Japan and Korea. In order to be able to do the assigned works well, each alumnus must supplement in many ways such as the re-training agency, short-term self-participation courses and advanced training courses. Expertise is hardware, alumni are equipped from studying in the school to do the job. Also, soft skills are the process of self-learning and self-training of each person to achieve success at work. Experts say that high graduation rankings will provide better job opportunities for students. The results of the interviews and surveys also show that the ranking rate is good to find a decent job, followed by a good rating and accountants with the average ranking often find it difficult to work. The higher the graduation rank, the better job opportunity and vice versa. This is the reason and the goal for students to strive to have a better and easier job. The excellent ranking rate is mainly responsible for more attractive job positions such as chief accountant, general accountant and auditing assistant. 


\section{University factor}

The influence of the school brand is one of the determinants that alumni have trouble getting a job. The alumni also lack confidence in applying for a job, even failing from the beginning of a job application review. This is a feedback channel on social assessment of the university's training.

Curriculum of the university has provided the knowledge necessary to do the accounting. However, the training program has not been appropriately distributed between theory and practice; there is no good combination between basic knowledge, professional skills and skills. Therefore, it is very necessary to have a correction of the training program to equip the knowledge and skills necessary for students, linking theory and practice, oriented towards the needs of society.

The content was trained either in the form of theory and academics, so the alumni were very surprised with the reality. Increasing the amount of practice or organizing field trips during the learning process helps students understand the problem and understand better application. Currently, there is not much training coordination of universities and firms. There is a lack of recruitment information as well as a combination of universities and employers. Vocational education in the universities is still formal and has not been focused.

\section{Part-time work before graduation}

One of the obstacles encountered when looking for jobs is the lack of work experience. Many alumni are concerned about their work experience before graduation. This reflects the current reality because the accounting profession requires a high level of expertise, employers always want people to work instead of retraining.

Today's students go to work not only to accumulate experience, seek job opportunities when they graduate, practice their professional skills, take advantage of their free time, want to assert themselves, expand and deliver to which a large part go to work longer to earn extra income, living expenses and service of the culture of passion and their dreams. However, not everyone can earn themselves extra jobs as they set out. Therefore, students can pay attention to two criteria: (i) regarding the content, nature of work and (ii) about the working environment. Types of jobs that accounting students do more before graduation are very diverse, such as: cashier, storekeeper, office staff, sales, business, tutor, magazine, waiter, etc. Most accounting students follow their specialties and professions, but there is still a significant proportion of students who must work for unrelated jobs. The fact that students work more helps them gain more experience of life, have better understanding of society but lacks a lot of basic knowledge. This is one of the downsides of doing more work (Nguyen, 2009).

\section{Related legal and policy environment}

The economy has many changes, the negative balance of the general crisis of the economy still remains, the supply is larger than the demand for labor and the state's policies in regulating labor, the firms fall into a state of dissolution, bankruptcy makes demand for labor decline, labor is much more fired, etc. These are some of the reasons influencing the post-graduation work of accounting students. After graduation, every alumnus is very eager to find jobs, both to earn a living income and to affirm themselves. Alumni can find jobs through various sources of information, but most of them are from advertising (direct from firms, job websites) and from referrals (friends and family, relatives, lecturers, etc.). Government policy in education is not appropriate. The education sector has no planning network of training institutions in accordance with the needs of human development of the country in general and each region. The increase of accounting training universities creates a large labor supply leading to labor redundancy. Students after graduation face difficulties in competition, especially from branded and prestigious schools.

\section{Information technology}

Information technology is going to strongly develop, the former accounting students face many limitations, and this is one of reasons influencing on the ability to find jobs. Mr. Vu - Director of the Department of Management and Supervision of Accounting and Auditing (Ministry of Finance) state that, with the rapid development of the digital technology era, if each accountant is not aware of the effects of the movement of the Industrial Revolution 4.0 to the accounting sector, he/she will be lagged behind and find it difficult to adapt to digital data sets. Besides, Mr. Vu - Oracle Vietnam Solution Architect said that, digital accounting will become the pillar to support commercial activities with customers and connect more essential department of the business. The digital breakthrough in accounting will create new trends, specifically, about $66 \%$ of small and medium firms will replace the services that accountants are currently performing with cloud services. $50 \%$ of small and medium firms will replace accountants if they do not adapt to cloud technology. Jobs that are easy to automate and replace with the most software include: Manual accounting entry, bookkeeping, year-end financial reporting, business activity report, salary, financial analysis main.

\section{Recommendations}

Based on the results, some recommendations are given in order to improve the post-graduate employment of accounting students. These recommendations focus on two determinants that have the greatest impacts on the employment of accounting graduates, i.e. accounting student factor and part-time job before graduation. 
For accounting student

The knowledge and skills of each person in terms of life, expertise, social relations are the determinants that determine their competitive advantage. The university time is just enough to provide the most basic knowledge and skills. Therefore, each alumnus must self-enlightenment that a degree is only a necessary but not enough condition, need to strengthen training and supplement basic soft skills to find a place stand on the labor market. Therefore, for alumni, students in accounting need to foster the necessary skills to be able to enhance their job opportunities. Students need to further improve on independent working and teamwork skills; communication skills, improve their language skills; strengthen skills in using computers and information technology applications; planning skills work and have a creative mind at work.

For part-time job before graduation

The extra work before graduation is not only a need, a desire but also an opportunity for students to experience work. However, students need to have a specific plan for arranging extra time and studying for students. Students need to understand the importance of learning and listening to lectures in class is essential to achieve high results in learning. Students should choose jobs that are relevant to their majors and work that will influence their formation and development in a positive way.

\section{References}

Begg, D., \& Fischer, S. (2000). Economics. sixth Edition, London, Mc Graw-Hill.

Hair, J.F, Anderson, R.E., Tatham, R.L., and Black, W.C. (2006). Multivariate data analysis. Prentice-Hall, International, Inc.

Hoang, T., \& Chu, N.M.N. (2008). Analysis of research data with SPSS. Hong Duc Publishing House.

Keynes, J.M. (1994). General theory of employment, interest rates, currencies. Education Publishing House.

Le, P.L., Chu, T.M.P., \& Nguyen, T.K.T. (2016). Determinants influencing the ability to have a job of the students in Foreign Trade University after graduation. Foreign Economic Relations, 84, 125 - 136.

Luong, M.D. (2008). The main solution is to meet the employment needs of rural workers in Phu Luong district, Thai Nguyen province. Master Thesis, Thai Nguyen University.

Luong, T.H. (2015). Some solutions to improve the quality of training through the work of homeroom teachers - academic advisors at universities, Education Journal, Special Number, 167-177.

Nguyen, B.N. (2013). Some solutions to improve the quality of highly qualified professional and technical labor to meet the requirements of developing the economy towards industrialization and modernization, State level research, Code KX.01.04/11-15.

Nguyen, Q. N., Tran, Q. A. \& Bui, V. T. (2011). Determinants influencing the Household income in rural areas of Tra On district, Vinh Long province, Science Journal, 5, 23-27.

Nguyen, X. L. (2009). The demand for extra work of students of the University of Foreign Languages - Hanoi National University: Situation and solutions, Psychology Journal, 9(126), 35-40.

Nguyen, T.K. (2014). Employment transformation in the Vietnamese economy in light of the Lewis-Fei-Ranis growth model of a labor-abundant economy. Journal of Economics and Development, 16(3), 49-67.

Tran, N. C. (2018). Three job search solutions for post-graduate students. From http://enternew.vn, May 5, 2018.

Tran, V. H. (2011). Salary structure of employees in firms, thematic research. Institute of Labor and Social Sciences, Hanoi.

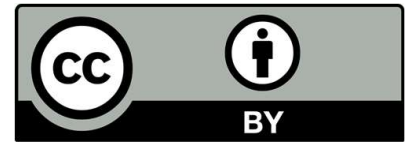

C 2020 by the authors; licensee Growing Science, Canada. This is an open access article distributed under the terms and conditions of the Creative Commons Attribution (CCBY) license (http://creativecommons.org/licenses/by/4.0/). 